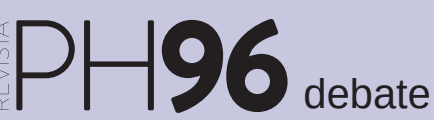

a debate Memoria democrática en la construcción de la historia y el patrimonio

| coordina Josefina Cuesta Bustillo

\title{
La exposición como medio de difusión y puesta en valor del papel de la mujer en el proceso de construcción de una memoria democrática
}

\author{
Jesica Serrano Granados | Universidad de Granada \\ URL de la contribución <www.iaph.es/revistaph/index.php/revistaph/article/view/4298>
}

Se entiende como memoria democrática el conjunto de aquellas acciones desarrolladas por los gobiernos de las diferentes comunidades autónomas de España para reivindicar a las víctimas de la guerra civil y del régimen franquista. Me gustaría tomar como punto de partida de esta aportación el último párrafo del texto introductorio de este debate "Solo cuando todos los españoles sean tratados por igual (...) solo cuando todas las clases de ciudadanos, también las ciudadanas y las minorías, y todas las memorias democráticas encuentren su hueco en las calles, en los monumentos, en los libros de texto, en el patrimonio inmaterial de nuestra cultura y de nuestras mentalidades, podremos hablar de una 'memoria en paz" con el fin de destacar la búsqueda de una igualdad real entre todos los ciudadanos y ciudadanas. En este sentido, si hablamos de memoria democrática creo de gran importancia dedicar un espacio en este debate al análisis de ciertas acciones que pretenden poner en valor a un colectivo que, en muchas ocasiones a lo largo de la historia, ha quedado relegado como es el constituido por las mujeres.

Las acciones que giran en torno a la recuperación de la memoria democrática se han llevado a cabo para reivindicar justicia hacia aquellas personas vinculadas con la lucha antifranquista que fueron represaliados durante la Guerra Civil española (1936-1930) y, posteriormente, por el régimen dictatorial (1939-1975). En este contexto, las mujeres constituyeron un colectivo que vio mermados sus derechos que hasta 1939 había conseguido a través de un proceso de lucha constante. Desde finales del siglo XIX hasta la II República, surgieron diferentes figuras que reivindicaron el feminismo en nuestro país y que especialmente durante los años del gobierno republicano vieron cumplidas muchas de sus reivindicaciones: el derecho al voto (1931), la ley de aborto y de divorcio (1936). A raíz del estallido de la Guerra Civil, las mujeres se organizaron en diferentes sectores para contribuir en la lucha antifascista accediendo a roles que hasta el momento habían sido relegados únicamente a los hombres. Al finalizar la guerra y la instauración de la dictadura, estas mujeres sufrieron una doble o triple represión basada no solo en su clase social o ideología política, sino también por el hecho de ser mujeres.

Reivindicar los avances de estas mujeres resulta fundamental para una democracia igualitaria en el presente. De esta manera, con el fin de desarrollar programas destinados a reivindicar su labor, hemos de partir de la difusión de esta parte de la historia, fundamental para crear conciencia de su importancia entre la sociedad. Por esta razón, a través de mi contribución me gustaría analizar la importancia de la exposición como medio de difusión. Desde el punto de vista patrimonial, es interesante utilizar la exposición como medio de comunicación y puesta en valor de nuestro colectivo, constituyendo el análisis documental de la labor expositiva un campo para la introducción de la perspectiva de género como categoría analítica.

El ejemplo en el que nos centraremos en este caso es la exposición titulada Las andaluzas y la política (19312006), organizada en el año 2006 con motivo de la celebración del 75 aniversario de la conquista del voto femenino por el Instituto Andaluz de la Mujer. Se trata de una exposición que toma como punto de partida la celebración del aniversario del sufragio universal en España en 1931 para desarrollar un análisis sobre los cambios de 


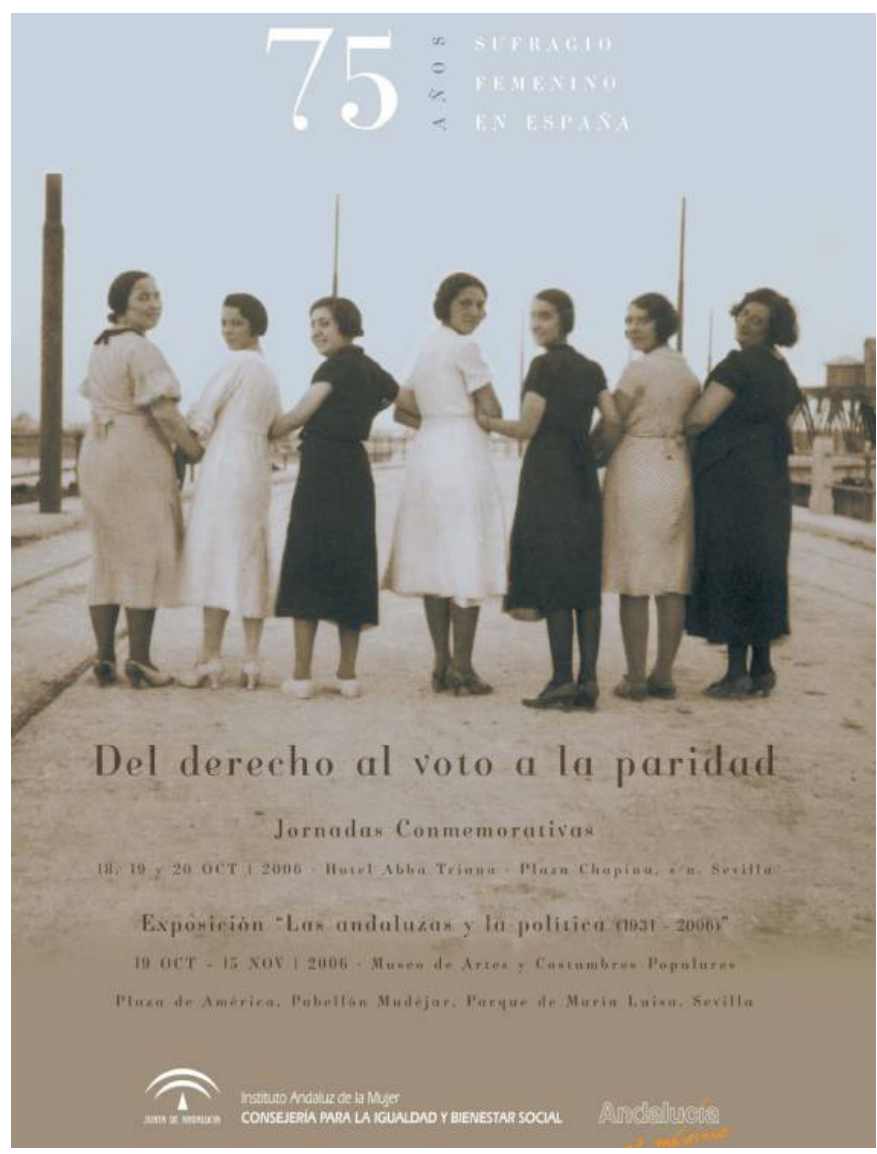

roles y los nuevos espacios a los que acceden las mujeres durante las primeras décadas del siglo XX, especialmente durante la II República, destacando el acceso a la educación y la política, aunque de forma muy restringida, y su posterior evolución durante la Guerra Civil, el régimen franquista y la transición.

Estos cambios en las relaciones de género, permitieron que tras el estallido del conflicto bélico en 1936 las mujeres se organizaran para contribuir en la lucha antifascista. La exposición pone de relevancia el cambio de roles y visibiliza el acceso de las mujeres a espacios atribuidos al género masculino como la miliciana en el frente, la mujer en armas, los puestos que ocupó en las fábricas desempeñado anteriormente por los hombres, así como aquellas que ocuparon puestos de secre- tario y dirección de diversas siglas políticas. Todas ellas, con la imposición del régimen dictatorial sufrieron una gran represión y vieron como de nuevo las relaciones de género de un cariz conservador que fueron implantadas por el régimen, las devolvían al rol de madre y cuidadora, limitada al hogar familiar.

El análisis mediante la perspectiva de género, nos permite observar cómo los roles desempeñados por hombres y mujeres se conforman a partir de una relación mutua en un contexto histórico y cultural concreto y, por lo tanto, permite destruir la consideración natural de las mismas. De ahí, su importancia para romper con las conductas de desigualad en el presente y comprender las que ocurrieron en la historia. Estas relaciones de género, al estar supeditas a un contexto cultural, se transforman fruto de cambios derivados de factores como el acceso a la educación y un contexto histórico marcado por un régimen político en buscar de una mayor igualdad, como podemos deducir del análisis de la exposición anteriormente citada.

A través de la crítica y el análisis de dicha exposición y otras muchas realizadas en torno a la mujer en la lucha por la democracia cabe destacar la importancia de aplicar la perspectiva de género a la hora de poner en valor el papel de las mujeres en el proceso de memoria democrática. La inclusión de la perspectiva de género, en este caso, nos permite asimismo observar como los pequeños cambios de roles basados en las diferencias de género, como el acceso a la educación, permiten cambiar las relaciones de género a niveles superiores, como el acceso a las cortes y, como consecuencia, el sufragio universal.

Para finalizar, me gustaría poner de relieve la importancia de iniciativas de difusión como la exposición Las andaluzas y la política (1931-2006) con el fin de ampliar su difusión a todos los sectores de la sociedad en tanto supone una labor fundamental para la concienciación de la sociedad hacia una memoria democrática igualitaria para todos los ciudadanos y ciudadanas. 